\title{
Gastrointestinal nematode control practices on lowland sheep farms in Ireland with reference to selection for anthelmintic resistance
}

\author{
Thomas Patten ${ }^{1,2}$, Barbara Good ${ }^{2 *}$, James P Hanrahan ${ }^{2}$, Grace Mulcahy ${ }^{1}$ and Theo de Waal ${ }^{1}$
}

\begin{abstract}
Gastrointestinal parasitism is a widely recognised problem in sheep production, particularly for lambs. While anthelmintics have a pivotal role in controlling the effects of parasites, there is a paucity of data on how farmers use anthelmintics. A representative sample of Irish lowland farmers were surveyed regarding their parasite control practices and risk factors that may contribute to the development of anthelmintic resistance. Questionnaires were distributed to 166 lowland Irish sheep producers. The vast majority of respondents treated their sheep with anthelmintics. Lambs were the cohort treated most frequently, the majority of farmers followed a set programme as opposed to treating at sign of disease. A substantial proportion (61\%) administered four or more treatments to lambs in a 'normal' year. Departures from best practice in anthelmintic administration that would encourage the development of anthelmintic resistance were observed. In conclusion, in the light of anthelmintic resistance, there is a need for a greater awareness of the principles that underpin the sustainable use of anthelmintics and practices that preserve anthelmintic efficacy should be given a very high priority in the design of helminth control programmes on each farm. To this end, given that veterinary practitioners and agricultural advisors were considered to be the farmer's most popular information resource, the capacity of these professions to communicate information relating to best practice in parasite control should be targeted.
\end{abstract}

\section{Background}

The contribution of helminth parasites to production and economic losses in ruminant production systems is widely recognised. Commercial sheep farming in Ireland, with the emphasis on meat production, is predominantly a lowland grassland-based system. In this context the most important parasites for grazing lambs are the gastrointestinal nematodes; primarily Nematodirus battus, which can result in high mortality, and Teladorsagia circumcincta plus Trichostrongylus species, which can cause substantial losses in productivity through lower weight gain. The advent of effective broad-spectrum anthelmintics to the marketplace meant that sheep producers could effectively control the negative impact that parasites have on performance. However, the development of anthelmintic resistance in parasitic populations threatens this

\footnotetext{
* Correspondence: Barbara.Good@teagasc.ie

${ }^{2}$ Teagasc, Animal Production Research Centre, Athenry, Co Galway, Ireland Full list of author information is available at the end of the article
}

approach. Treatment frequency, the proportion of the population exposed to the anthelmintic, inappropriate dose rate and movement of sheep containing drug resistant worm populations are considered important factors influencing the rate of development and prevalence of drug resistance [1-3].

While expenditure on anthelmintics for livestock in Ireland accounts for approximately $25 \%$ of the animal health market [4], there is no information available on the cost of specific parasite control practices for sheep. With some evidence of anthelmintic resistant parasites in Ireland [5-8] and no published information on parasite control strategies used by Irish sheep producers, the purpose of this study was to obtain information on parasite control strategies on lowland sheep farms that would inform dialogue on sustainable parasite control practices. The results of the questionnaire are outlined with emphasis on farm details and on grazing management and parasite treatment practices.

\section{()




\section{Methods}

\section{Questionnaire}

A questionnaire relating to farm details, grazing management and parasite treatment practices was designed. Prior to administering the final draft to the target population the questionnaire was piloted to ten Teagasc (Irish Agriculture and Food Development Authority) staff members, for feedback and subsequent amendment. Questions about farm profile related to the previous year while questions on parasite control practices related to typical practice in a 'normal' year.

The questionnaire (38 questions) was divided into two sections. Section 1 incorporated general questions relating to the farm and the management system (e.g., farm size, number and breed of sheep, grazing and meal feeding practices). Section 2 contained specific questions on practices for control of gastrointestinal parasites (e.g., frequency, timing and type of treatment and factors governing the choice of anthelmintic used).

\section{Selection of farms}

The target population in this study was sheep producers (clients of Teagasc) where sheep formed a major part of the farm enterprise for a long period and who had more than 100 breeding ewes. A total of 166 farmers were selected for this study and were either from sheep producers already involved in a Teagasc study, on technology evaluation and transfer [9] or from farmers identified by Teagasc advisors. Advisors located throughout the country were asked to nominate three to five farms from their region.

\section{Data management and statistical analysis}

Data were entered in duplicate on Excel spreadsheets (unanswered questions were left as blank) and screened using SAS procedures [10]. Any anomalies were checked and corrected.

Results are presented as percentages. The absolute numbers on which the percentages were based are in parentheses.

\section{Results}

\section{Response to questionnaire}

Questionnaires were returned by $70 \%$ of recipients ( $\mathrm{n}=$ 117 respondents). However, 13 respondents were subsequently excluded from analysis as the number of breeding ewes per flock was either less than $100(n=7)$ or information was missing $(n=6)$. In all cases the reported percentages represent the percentage of those who responded to the question.

\section{Farm profile}

Livestock and enterprise details are summarised on Tables 1, 2, and 3. The majority of respondents (63\% [65]) had both a sheep and cattle enterprise (Table 1). Suffolk was the dominant breed with Suffolk cross ewes and Suffolk rams in $41 \%$ and $42 \%$ of flocks, respectively (Table 2). Flock replacements were homebred on 51\% (58) of farms. The majority of respondents 96\% (99) housed their sheep during the winter. March was the most frequently selected month for lambing, with $83 \%$ (86) of all farms indicating it as one of their target lambing months (January 14\% [15], February 27\% [28], March 83\% [86], April 34\% [35], May 4\% [4]). Set stocking was reported on 19\% (19) of all farms. Rotational grazing was the most popular system, and was reported on 78\% (80) of all farms; the remaining 3\% (3) incorporated both systems into their grazing plan (Table 3 ). Where the enterprise was cattle plus sheep, the majority, $72 \%$ (46), practiced mixed grazing.

Table 1 Farm parameters, number of farms, means and ranges on the different types of enterprise

\begin{tabular}{|c|c|c|c|c|c|c|}
\hline & \multicolumn{2}{|c|}{ Sheep only } & \multicolumn{2}{|c|}{ Sheep and Cattle } & \multicolumn{2}{|c|}{ All enterprises } \\
\hline & Mean (n) & Range & Mean (n) & Range & Mean (n) & Range \\
\hline \multicolumn{7}{|l|}{ Sheep } \\
\hline LSU/ha & $2.10(39)$ & & $1.65(65)$ & & $1.82(104)$ & \\
\hline Flock size (breeding ewes) & $446(39)$ & $117-1250$ & $342(65)$ & $105-2000$ & $381(104)$ & $105-2000$ \\
\hline \multicolumn{7}{|c|}{ Lambs purchased for: Finishing } \\
\hline $\begin{array}{l}\text { Finishing } \\
\text { breeding }\end{array}$ & $374(5)$ & $40-780$ & $276(9)$ & $23-500$ & $311(14)$ & $23-780$ \\
\hline replacements & $85(20)$ & $16-165$ & $59(38)$ & $20-136$ & $68(58)$ & $16-165$ \\
\hline \multicolumn{7}{|l|}{ Cattle } \\
\hline Number of cows & NA & NA & $43(55)$ & $1-140$ & $43(55)$ & $1-140$ \\
\hline \multicolumn{7}{|l|}{ Number of cattle: } \\
\hline$<1$ year & NA & NA & $43(54)$ & $8-150$ & $43(54)$ & $8-150$ \\
\hline $1-2$ years & NA & NA & $40(54)$ & $4-200$ & $40(54)$ & $4-200$ \\
\hline$>2$ years & NA & NA & $12(33)$ & $1-150$ & $12(33)$ & $1-150$ \\
\hline
\end{tabular}


Table 2 Ewe and ram breed types on the different types of enterprise

\begin{tabular}{lccc}
\hline & $\begin{array}{c}\text { Sheep only } \\
(\mathbf{n}=\mathbf{3 9}) \\
\%(\mathbf{n})\end{array}$ & $\begin{array}{c}\text { Sheep and Cattle } \\
(\mathbf{n}=\mathbf{6 5}) \\
\%(\mathbf{n})\end{array}$ & $\begin{array}{c}\text { All enterprises } \\
(\mathbf{n}=\mathbf{1 0 4}) \\
\%(\mathbf{n})\end{array}$ \\
\hline Ewe breed & & & \\
Mostly Suffolk cross & $41(16)$ & $42(27)$ & $41(43)$ \\
Mostly Texel cross & $8(3)$ & $2(1)$ & $4(4)$ \\
Other & $3(1)$ & $9(6)$ & $8(7)$ \\
Combination & $49(19)$ & $48(31)$ & $48(50)$ \\
& & & \\
Ram breed & & & \\
Mostly Suffolk & $50(14)$ & $52(30)$ & $42(44)$ \\
Mostly Texel & $39(11)$ & $26(15)$ & $25(26)$ \\
Both & $11(3)$ & $22(13)$ & $15(16)$ \\
\hline
\end{tabular}

Details on additional nutritional supplementation (concentrate/minerals) practices are shown in Table 3. The majority, 69\% (70) of respondents reported feeding concentrates to lambs at grass (Table 3), which began preweaning in $71 \%$ of cases (Table 3). Sheep were supplemented with extra minerals on $81 \%$ (84) of farms.

Table 3 Details of grazing system, concentrate feeding and mineral supplements

\begin{tabular}{|c|c|}
\hline & $\begin{array}{c}\text { Respondents } \\
\%(\mathrm{n})\end{array}$ \\
\hline \multicolumn{2}{|l|}{ Grazing system: } \\
\hline Set stocking & $19(19)$ \\
\hline Rotational & $78(80)$ \\
\hline Both & $3(3)$ \\
\hline Mixed grazing & $45(46)$ \\
\hline Separate grazing & $52(54)$ \\
\hline Both & $3(3)$ \\
\hline Concentrate feeding to lambs: & $69(70)$ \\
\hline Start pre-weaning & $71(47)$ \\
\hline Fed to appetite & $44(30)$ \\
\hline$<20 \mathrm{~kg}$ & $38(26)$ \\
\hline$>20 \mathrm{~kg}$ & $19(13)$ \\
\hline Administered minerals: & $81(84)$ \\
\hline Cobalt & $70(73)$ \\
\hline Copper & $29(30)$ \\
\hline Selenium & $26(27)$ \\
\hline Other & $16(17)$ \\
\hline \multicolumn{2}{|l|}{ Method of administration: } \\
\hline In feed & $19(17)$ \\
\hline Separate dose & $57(50)$ \\
\hline With anthelmintic & $7(6)$ \\
\hline Some combination of 2 of the above choices & $17(15)$ \\
\hline
\end{tabular}

Cobalt was the predominant mineral given (70\% [73]) followed by copper (29\% [30]), and selenium (26\% [27]). A smaller number of respondents (16\% [17]) indicated giving minerals other than those specified (Cobalt, Copper or Selenium).

\section{Control of gastrointestinal parasites}

Details of treatment practices are shown in Table 4. The vast majority of farmers indicated that they followed a set treatment programme for their stock. The estimated number of treatments given to ewes, lambs and rams in a 'normal' year are shown in Figure 1. Both ewes and rams were treated less frequently than lambs with the majority of ewes and rams receiving one or two treatments. A substantial proportion, $61 \%$ (60), administered 4 or more treatments to lambs in a 'normal' year. The most popular time indicated by the respondents to treat ewes was at housing (68\% [71]), and premating (55\% [57]) (Table 4). The majority (72\% [75]) indicated dosing lambs before moving to aftergrass (Table 4). The majority of respondents indicated that they would treat all ewes $(97 \%$ [98]) or lambs (100\% [101]) in a particular group at any given time as opposed to selectively treating some individuals.

Table 4 Treatment practices for gastrointestinal nematodes for the different age and sex of the sheep

\begin{tabular}{llll}
\hline & Lambs & Ewes & Rams \\
$\%(n)$ & $\%(n)$ & $\%(n)$ \\
\hline
\end{tabular}

Decording to:

Set programme

Sign of disease

Time when animals dosed:

At housing
Before moving to
aftergrass
Pre-mating
Pre-lambing
Post-lambing

$15(16) \quad 68(71) \quad 44(46)$

$72(75)$

$20(21)$

$23(24)$

$55(57) \quad 60(62)$

$14(14)$

$32(33)$

Weight basis for dosing:

Heaviest actual

Heaviest guessed

Average guessed

Heaviest: actual +

guessed

Combination of all 3

$\begin{array}{lll}54(55) & 33(32) & \mathrm{ND} \\ 29(30) & 43(42) & \mathrm{ND} \\ 16(16) & 22(22) & \mathrm{ND} \\ 1(1) & 1(1) & \mathrm{ND} \\ & & \\ & 1(1) & \mathrm{ND}\end{array}$

\begin{tabular}{llll}
$\begin{array}{l}\text { Withold food prior to } \\
\text { dosing: }\end{array}$ & $30(31)$ & $27(28)$ & ND \\
$>12 \mathrm{~h}$ & $7(2)$ & $12(3)$ & $\mathrm{ND}$ \\
$\quad$ Keep in after dosing: & $27(28)$ & & $\mathrm{ND}$ \\
\hline
\end{tabular}




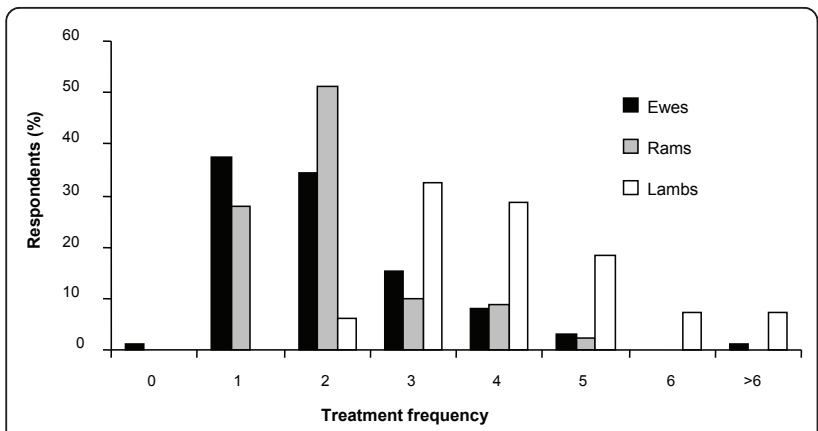

Figure 1 Annual frequency of anthelmintic treatments administered to ewes, rams and lambs.

A summary of responses in relation to how the amount of anthelmintic administered to ewes and lambs was calculated is shown on Table 4 . Over $45 \%$ (46) of farmers (greater in ewes than lambs) indicated some element of guesswork in their weight calculations. Most respondents indicated they would weigh lambs and dose according to the heaviest lamb in the group (54\% [55]) while for ewes a greater proportion of respondents indicated they would guess the weight of the heaviest ewe and dose accordingly (43\% [42]). The accuracy of the dosing gun was always checked on $59 \%$ (60) of farms with $34 \%$ (35) stating they 'sometimes' checked the accuracy of the dosing gun.

The practice of withholding food before dosing lambs or ewes was reported by approximately $30 \%$ of respondents (Table 4), of whom a minority indicated the fasting period was greater than 12 hours. Twenty-seven percent (28) of respondents reported keeping their animals off pasture after treating with an anthelmintic. The duration of the holding period varied between one and six hours.

Benzimidazoles and macrocyclic lactones were the anthelmintic classes of choice on all farms, with levamisole proving the least popular of the three classes (Figure 2). The factors that respondents indicated influenced their choice of anthelmintic product are

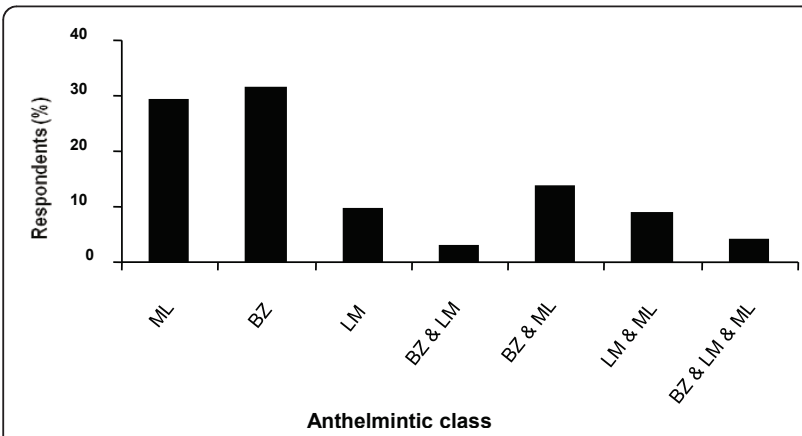

Figure 2 Class of anthelmintic used in previous year. ( $M L=$ Macrocyclic Lactones, BZ = Benzimidazoles, $\mathrm{LM}=$ Levamisole). summarised in Figure 3. The majority of respondents indicated that past experience of the product was the most influential factor.

The frequency with which farmers changed the anthelmintic product used is shown in Figure 4. The majority of sheep producers, 58\% (57), indicated they switched anthelmintic class on an annual basis while $25 \%$ (25) indicated that the duration between switching was longer than one year.

Over one third of respondents (37\% [38]) believed that anthelmintic products were not working as well as in previous years. Of these the majority, $82 \%$ (31), indicated that the benzimidazoles were not as effective, while dissatisfaction with levamisole and macrocyclic lactones was $32 \%$ (12) and $21 \%$ (8), respectively. Twelve per cent of respondents reported that parasite resistance to anthelmintics had been confirmed in their flock.

Figure 5 provides a summary of reponses regarding ewe and lamb movement to graze 'clean' pasture postanthelmintic treatment.

The majority of respondents (94\% [98]) treated purchased animals with an anthelmintic before mixing them with their own flock. Of these, 32\% (29) indicated that the anthelmintic they would use would be a different product to that used for the flock in the current year. The majority of respondents $(71 \%$ [20]) treated with a macrocyclic lactone.

\section{Discussion}

From this survey it is evident that anthelmintics are an integral part of parasite control strategies. However, the gastrointestinal nematode control practices revealed by the survey highlight the need for communication on 'best' dosing practices. Departures from these 'best' practices will encourage the development and spread of anthelmintic resistance. Despite the widely available information on appropriate dosing practices the results indicate a lack of implementation of some of the basics,

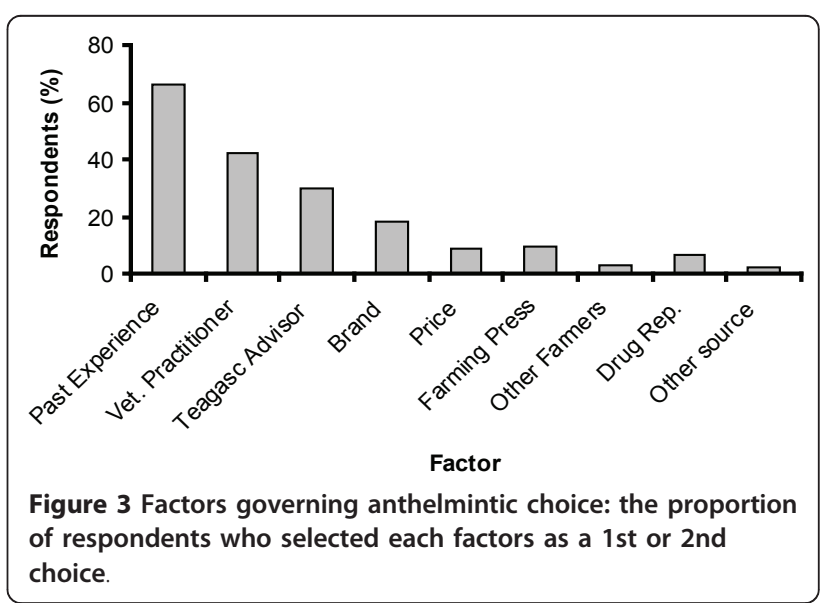




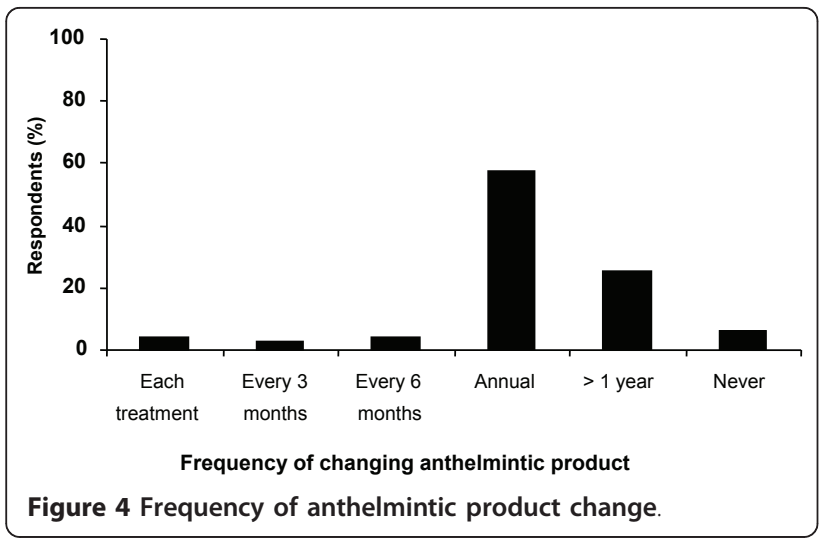

such as how the dose rate is determined and whether dosing equipment is checked before use. If a sub-optimal amount is administered this will increase the selection pressure for resistant worms [11-15] and result in a poor anthelmintic response, which may in turn select for anthelmintic resistance [3] and lead to the need for more dosing.

In the current climate of emerging anthelmintic resistance it is clear that parasite control practices that were used in the past and yielded favourable production outcomes in terms of managing parasites must be re-evaluated. Strategies based on suppressive and frequent treatments will select strongly for resistance and do not represent a sustainable approach to parasite control in general. Results on frequency of treatment revealed, unsurprisingly, that ewes and rams were treated less frequently than lambs for gastrointestinal parasites. The treatment frequency in lambs does suggest that a suppressive anthelmintic treatment strategy was being used on the majority of farms. Moreover, the routine treatment of adult sheep needs to be questioned. For instance, ewes pre-mating will generally have a low parasite burden and will not benefit from anthelmintic treatment. As pasture contamination in the autumn/ winter will also be lower, treatment of ewes at this time

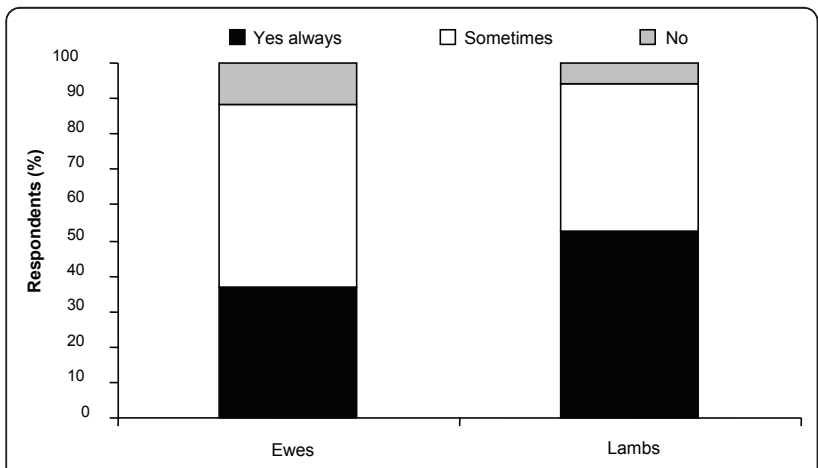

Figure 5 Movement to 'clean' grazing post treatment. will select for anthelmintic resistance as any worms that survive treatment will have a prolonged reproductive advantage and so become the dominant contributor to infection on pasture [16]. It is now regarded that treatment of ewes pre-mating should be restricted to ewes in poor condition or ewe lambs.

Withholding feed from livestock for 12 hours prior to the administration of an oral benzimidazole or macrocyclic lactone has been reported as a good practice in achieving improved efficacy of these drugs $[17,18]$. While $30 \%$ of respondents indicated they withheld feed prior to administration of drugs (question did not ask to specify class of drug), the withholding period was not the recommended 12 hours for the majority of respondents. Withholding food for less than 12 hours has minimal impact on anthelmintic efficacy.

Another factor considered to increase the risk of developing resistance on a farm is the inadvertent importation of drug-resistant worms in purchased sheep. The practices of treating and quarantining purchased animals and delaying the move of treated stock to 'clean' pasture are now considered important in curbing the spread of resistance [16]. While almost all farmers $(94 \%)$ reported that purchased animals were treated with an anthelmintic prior to mixing with the rest of the flock, $68 \%$ indicated this would be with the anthelmintic being used in the current year. Up until recently, in light of the high prevalence of benzimidazole resistance, it was recommended that purchased sheep be treated sequentially with macrocyclic lactone and levamisole to minimise the risks involved [16]. With increasing reports of resistance to ivermectin and levamisole and the advent of a fourth class of anthelmintic on the market the advice has become more specific in that moxidectin (3-ML) and monepantel (4-AD) are ideally used as quarantine treatments. While there is no critical evidence to support the proposition that the annual alternation of anthelmintic class slows the development of resistance $[11,19]$, results from this survey clearly indicate this message has been widely accepted.

In the past 'drench/treat and move' to 'safe' pasture was a globally recommended parasite control practice for lambs $[3,20]$ which, providing drug efficacy was high, ensured that 'safe' pasture maintained this minimally contaminated status for a longer period thus negating the need for frequent treatment of young livestock. Van Wyk [3] has questioned the wisdom of this system, indicating that it can hasten the development of resistance as the anthelmintic resistant worms, that have survived treatment, will be the dominant contributor to the population on the 'safe' pasture. Conder and Campbell [11] state that drench-and-move systems should be considered only on a case-by-case basis and not for widespread use. Today it is commonly listed as a practice to 
be avoided especially on farms where resistance is a problem $[3,16,21,22]$.

Research results have indicated that improved nutrition (metabolisable protein) enhances the host's resilience to parasites [23]. As an extension to this, one might expect that lambs being fed concentrate are less exposed to parasite challenge and as such should need fewer treatments. In this study, the absence of any evidence for this is probably a reflection of the set approach to treatment used by the majority of respondents. Moreover, it was interesting to note that while the enterprises did differ in the number of livestock units per hectare this did not impact on the number of anthelmintics administered.

Overall, the evidence indicates a need for a greater awareness of the principles that underpin the sustainable use of anthelmintics and the practices that preserve anthelmintic efficacy should be given a very high priority in the design of helminth control programmes on each farm. To this end, the potential of veterinary practitioners and agricultural advisors as sources of information on best practice should be targeted.

\section{Acknowledgements}

The co-operation of participants is gratefully acknowledged. We would also like to acknowledge Dr. Dave Bartley (Moredun Research Institute, Scotland) and Andrew Kinsella, Pat Clarke and Gerry Scully (Teagasc).

\section{Author details}

'UCD School of Agriculture, Food Science and Veterinary Medicine, University College Dublin, Dublin 4, Ireland. ${ }^{2}$ Teagasc, Animal Production Research Centre, Athenry, Co Galway, Ireland.

\section{Authors' contributions}

TP Compiled the questionnaire, entered and evaluated the data and was joint lead author of the manuscript. BG, GM and TDW conceived the study, participated in the design and co-ordination. BG performed the statistical analysis and was joint lead author of the manuscript. JPH provided advice on study design, statistical analysis and participated in writing of the manuscript. TDW provided advice on data analysis and participated in writing of the manuscript. All authors read and approved the final manuscript.

\section{Competing interests}

The authors declare that they have no competing interests.

Received: 18 November 2010 Accepted: 31 March 2011

Published: 31 March 2011

\section{References}

1. Coles G: Moving backwards on resistance. Vet Rec 2000, 147:24.

2. Coles G: Sustainable use of anthlemintics in grazing animals. Vet Rec 2002, 151:165-169

3. van Wyk J: Refugia-overlooked as perhaps the most potent factor concerning the development of anthelmintic resistance. Onderstepoort Vet Res 2001, 68:55-67.

4. Animal \& Plant Health Association, Ireland. [http://www.apha.ie].

5. O'Brien DJ: Anthelmintic resistance in sheep. Irish Vet News 1992, 14:25-26.

6. O'Brien DJ, Strickland KL, Parr SL, Gray JS, O'Reilly PF, Clements L, Dwyer PJ, O'Reilly LM, Coles GC, Borgsteede FHM, Geerts S: Anthelmintic resistant nematodes in farm animals in Ireland. In Anthelmintic Resistance in Nematodes of Farm Animals. A Seminar Organised for the European
Commission, 8-9 November 1994; Brussels Edited by: Coles GC, Borgsteede FHM 1994, 101-106.

7. Parr SL, Gray JS: A preliminary survey of the prevalence of benzimidazole resistance in gastro-intestinal nematodes of sheep in the Republic of Ireland. Proceedings of the 18th Annual Research Meeting of the Irish Grassland and Animal Production Association: 3 April 1992; UCD, Ireland 1992, 3-4.

8. Good B, Hanrahan JP, Kinsella A: Anthelmintic resistance in sheep roundworms - preliminary observations. Proceedings of the Agricultural Research Forum: March 2003: Tullamore 2003, 78.

9. Faughnan J, Hanrahan JP, Nolan T: Investigation of management factors responsible for farm to farm variation in lamb growth rate. Proceedings of the Agricultural Research Forum: March 2004: Tullamore 2004, 23.

10. SAS Institute Inc: SAS/STAT User's Guide, Version 8.2 North Carolina: SAS institute, Inc Cary; 2000.

11. Conder GA, Cambell WC: Chemotherapy of nematode infections of veterinary importance, with special reference to drug resistance. Adv Parasitol 1995, 35:1-84.

12. Jackson F, Coop RL, Jackson E, Little S, Russel AJ: Anthelmintic resistant nematodes in goats. Vet Rec 1991, 129:39-40.

13. Prichard RK: Interaction of host physiology and efficacy of antiparasitic drugs. Vet Parasitol 1985, 18:103-110.

14. Prichard RK: Anthelmintic resistance in nematodes; extent, recent understanding and future directions for control and research. Int $J$ Parasitol 1990, 20:515-523.

15. Waller PJ: The development of anthelmintic resistance in ruminant livestock. Acta Tropica 1994, 56:233-243.

16. Abbot KA, Taylor M, Stubbings LA: Sustainable worm control strategies for sheep. 3 edition. Packington, UK: Context Publications; 2009

17. Ali DN, Hennessey DR: The effect of feed intake on the rate of flow of digesta and the disposition and activity of oxfendazole in sheep. Int $J$ Parasitol 1993, 23:477-478.

18. Ali DN, Hennessey DR: The effect of feed intake on the pharmacokinetic deposition and efficacy of ivermectin in sheep. J Vet Pharmacol Ther 1996, 23:89-94.

19. Waller PJ, Donald AD, Dobson RJ, Lacey E, Hennessy DR, Allerton GR, Prichard RK: Changes in anthelmintic resistance status of Haemonchus contortus and Trichostrongylus colubriformis exposed to different anthelmintic selection pressures in grazing sheep. Int J Parasitol 1989, 19:99-110.

20. Michel JF: The epidemiology and control of some nematode infections in grazing animals. Adv Parasitol 1976, 14:355-397.

21. Barger IA: Control by management. Vet Parasitol 1998, 72:493-506

22. Coles G: Strategies to minimise anthelmintic resistance in large animal practice. In Practice 2003, 25:494-499.

23. Coop R, Kyriazakis I: Nutrition - parasite interaction. Vet Parasitol 1999, 84:187-204.

doi:10.1186/2046-0481-64-4

Cite this article as: Patten et al:: Gastrointestinal nematode control practices on lowland sheep farms in Ireland with reference to selection for anthelmintic resistance. Irish Veterinary Journal 2011 64:4.

\section{Submit your next manuscript to BioMed Central and take full advantage of:}

- Convenient online submission

- Thorough peer review

- No space constraints or color figure charges

- Immediate publication on acceptance

- Inclusion in PubMed, CAS, Scopus and Google Scholar

- Research which is freely available for redistribution 